\title{
POLÍTICAS DE FORMAÇÃO E VALORIZAÇÃO DOCENTE: UMA ANÁLISE DO PLANO DE DESENVOLVIMENTO DA EDUCAÇÃO E DAS METAS DO NOVO PLANO NACIONAL DE EDUCAÇÃ̃O
}

\author{
Janaína Silvana SOBZINSKI ${ }^{1}$ \\ Emilli Moreira DIOGO ${ }^{2}$ \\ Gisele MASSON ${ }^{3}$
}

RESUMO: Este artigo tem como objetivo analisar como a formação e a valorização docente estão contempladas nas políticas educacionais. A pesquisa realizada foi bibliográfica e documental, fundamentada no materialismo histórico e dialético. Os documentos utilizados foram o Plano de Desenvolvimento da Educação (BRASIL, 2007c), o Projeto de Lei $n^{\circ} 8.035 / 2010$ (BRASIL, 2010b) e o Projeto de Lei $n^{\circ}$ 103/2012 (BRASIL, 2012), os quais dizem respeito ao novo Plano Nacional de Educação, bem como os documentos com proposições de emendas de diferentes entidades e as que foram incorporadas pelo Fórum Nacional de Educação (BRASIL, 2011). O estudo realizado identificou que os objetivos estabelecidos pelo Plano de Desenvolvimento da Educação (BRASIL, 2007c) e as metas do novo Plano Nacional de Educação (BRASIL, 2014), para a formação e valorização docente, não consideram as condições objetivas, como infraestrutura das escolas, jornada de trabalho num único estabelecimento, materiais didáticos adequados, entre outras necessidades. Por fim, destacamos que a formação e a valorização dos professores devem estar atreladas à luta por melhores condições de trabalho. Para tanto, há necessidade de maior investimento na educação, através de políticas de curto, médio e longo prazo, de maior valorização dos professores e de uma sólida formação dos docentes e alunos, com o objetivo de possibilitar transformações educacionais qualitativas que contribuam para a formação humana.

PALAVRAS-CHAVE: Políticas de formação. Valorização docente. Plano Nacional da Educação. Plano de Desenvolvimento da Educação.

\section{INTRODUÇÃO}

A educação, em geral, é imprescindível para o processo de reprodução e de transformação social, pois é através dela que é possível garantir o desenvolvimento da sociabilidade e da cultura. Entretanto, na sociedade capitalista, a educação assume,

\footnotetext{
${ }^{1}$ Mestranda do Programa de Pós-graduação em Educação. UEPG - Universidade Estadual de Ponta Grosa. Ponta Grossa - PR - Brasil. 84030-900 - janainasobzinski@ yahoo.com.br.

${ }^{2}$ Mestranda do Programa de Pós-graduação em Educação. UEPG - Universidade Estadual de Ponta Grosa. Ponta Grossa - PR - Brasil. 84030-900 - emillimoreira@bol.com.br.

${ }^{3}$ Doutora em Educação. UFSC - Universidade Federal de Santa Catarina. Professora do Departamento de Educação e do Programa de Pós-Graduação em Educação. Mestranda do Programa de Pós-graduação em Educação. UEPG - Universidade Estadual de Ponta Grosa. Ponta Grossa - PR - Brasil. 84030-900 gimasson@uol.com.br.
} 
hegemonicamente, o papel de garantir a transmissão de valores e conhecimentos necessários para a legitimação da relação antagônica entre capital e trabalho.

No que diz respeito à formação e à valorização de professores, é necessário, para a sua compreensão, a consideração do contexto econômico, social e político, mais amplo, e do contexto mais específico das instituições formadoras, dos sistemas educacionais e redes de escolas. Desta forma, é importante e necessário que se desenvolvam pesquisas que analisem e reflitam sobre esses contextos, que acabam por se entrelaçar, a fim de desvelar a realidade e contribuir para mudanças essenciais.

Verificamos que as políticas educacionais de formação e de valorização dos professores não têm sido suficientes para a garantia de melhores condições de trabalho, já que a realidade demonstra que a educação e a profissão docente estão em crise, consequência dos diferentes problemas sociais da atualidade. Assim, julgamos que a contribuição do materialismo histórico dialético é importante para o conhecimento da realidade, a partir dos antagonismos e contradições sociais. Desta forma, consideramos que a luta por melhorias na educação não pode estar desvinculada da luta pela superação da atual forma de organização social.

Mészáros (2002) em sua obra "Educação para além do capital” defende que:

[...] o papel da educação é soberano, tanto para a elaboração de estratégias apropriadas e adequadas para mudar as condições objetivas de reprodução, como para a automudança consciente dos indivíduos chamados a concretizar a criação de uma ordem social metabólica radicalmente diferente. É isso que se quer dizer com a concebida "sociedade de produtores livremente associados". Portanto, não é surpreendente que na concepção marxista a "efetiva transcendência da auto-alienação do trabalho" seja caracterizada como uma tarefa inevitavelmente educacional. (MÉSZÁROS, 2002, p.65, grifo do autor).

Buscamos, assim, estabelecer uma reflexão sobre as políticas educacionais voltadas à formação e à valorização dos professores, especialmente sobre o Plano de Desenvolvimento da Educação (BRASIL, 2007c) amplamente divulgado pelo MEC no livro "O Plano de Desenvolvimento da Educação: razões, princípios e programas" (BRASIL, 2007c), e sobre as metas do Plano Nacional da Educação (PNE/2011-2020), previsto para a próxima década.

Desse modo, destacamos os objetivos principais do estudo realizado: a) analisar as contribuições e os limites do Plano de Desenvolvimento da Educação - PDE (BRASIL, 2007c) e das emendas propostas para o novo Plano Nacional de Educação - 
PNE (BRASIL, 2014) para a formação e valorização de professores; b) destacar a importância do debate em torno da definição de um Plano Nacional da Educação; c) identificar as concepções de formação de professores expressas no PDE e no PNE e quais as suas possíveis influências na educação.

Num primeiro momento, apresentamos considerações a respeito da formação e valorização docente com ênfase no Plano de Desenvolvimento da Educação (BRASIL, 2007c). Tal análise foi realizada com foco no documento: "O Plano de Desenvolvimento da Educação: razões, princípios e programas" (BRASIL, 2007c), o qual foi lançado oficialmente no dia 24 de abril de 2007, simultaneamente ao Decreto $\mathrm{n}^{\circ}$ 6.094 (BRASIL, 2007a), que estabeleceu o Plano de Metas Compromisso Todos pela Educação. Num segundo momento, analisamos as metas propostas no Projeto de Lei $\mathrm{n}^{\circ}$ 8.035/2010 ${ }^{4}$ no Projeto de Lei da Câmara - PLC n ${ }^{\circ}$ 103/2012 e o que foi mantido ou excluído na Lei n ${ }^{\circ}$ 13.005/2014 (BRASIL, 2014) que instituiu o novo Plano Nacional da Educação. Para as análises, destaca-se a contribuição do materialismo histórico e dialético para a compreensão da realidade, sendo considerado como concepção e método que traz muitas contribuições nos estudos das políticas educacionais.

\section{Plano de desenvolvimento da educação: uma análise da formação e valorização docente}

As discussões sobre o tema "formação docente" são inúmeras, já o tema da "valorização docente" nem sempre recebe a atenção devida. Todavia, ambos os assuntos são retratados nos documentos das políticas educacionais, pois se destaca que a valorização do professor na Educação Básica é um dos aspectos importantes para que ocorra a melhoria da educação.

O documento que apresenta as propostas do Plano de Desenvolvimento da Educação (BRASIL, 2007) foi apresentado no dia 15 de março de 2007 e lançado no dia 24 de abril do mesmo ano, ao mesmo tempo em que se estabeleceu o Decreto $n^{\circ} 6.094$ (BRASIL, 2007a), que dispõe sobre a implementação do Plano de Metas “Compromisso Todos pela Educação", considerado como fundamento do PDE.

O Plano de Desenvolvimento da Educação (BRASIL, 2007c), que apesar de se pautar nos aspectos previstos no PNE, para Saviani (2007), diferentemente deste, não é uma política de Estado, pois assume características de política de governo, já que esta é

${ }^{4} \mathrm{O}$ número de emendas propostas ao Projeto de Lei $\mathrm{n}^{\mathrm{o}}$ 8.035/2010 totalizaram 2.906, sendo 66 relacionadas à formação e valorização docente (BRASIL, 2010b). 
realizada por um governo, em um determinado período de seu mandato. Assim, pode mudar o governo e, com ele, os objetivos que estão previstos neste plano (grifo nosso).

Os termos política de Estado e política de governo são definidos por Oliveira (2011, p.329, grifo nosso) da seguinte forma:

Considera-se que políticas de governo são aquelas que o Executivo decide num processo elementar de formulação e implementação de determinadas medidas e programas, visando responder às demandas da agenda política interna, ainda que envolvam escolhas complexas. Já as políticas de Estado são aquelas que envolvem mais de uma agência do Estado, passando em geral pelo Parlamento ou por instâncias diversas de discussão, resultando em mudanças de outras normas ou disposições preexistentes, com incidência em setores mais amplos da sociedade.

Saviani (2009) estabelece uma análise crítica do PDE. Segundo ele, com exceção do "Livro sobre o PDE", todas as demais 40 ações incidem sobre aspectos já previstos no PNE, pois, a partir de uma confrontação entre a estrutura do PNE e do PDE, conclui-se que o segundo não se constitui como um plano. Saviani (2009, p.27) considera que o PDE “[...] define-se antes, como um conjunto de ações, que, teoricamente, se constituíram em estratégias para a realização dos objetivos e metas previstos no PNE".

No Plano de Desenvolvimento da Educação (BRASIL, 2007c) estão previstas dezessete ações para a Educação Básica, sendo doze em caráter global e cinco específicas aos diferentes níveis de ensino. Dentre as ações que o plano estabelece para a Educação Básica, situa-se o FUNDEB, o Plano de metas do PDE-IDEB, os programas "Piso do Magistério" e "Formação". As ações do PDE estendem-se, também, para o Ensino Fundamental, Educação Superior, Educação de Jovens e Adultos (EJA), Educação Especial e Educação Tecnológica e Profissional, somando-se quarenta ações no total.

A primeira proposição encontrada no livro sobre o PDE, na abertura do segundo capítulo é que: “[...] um dos principais pontos do PDE é a formação de professores e a valorização dos profissionais da educação. A questão é urgente, estratégica e reclama resposta nacional.” (BRASIL, 2007c). Com isso, percebe-se que a formação docente é concebida como uma necessidade e, ao mesmo tempo, coloca-se em evidência que a solução para a melhoria na qualidade educacional depende das ações dos professores. 
A proposta presente no PDE, para a formação docente, prioriza a Universidade Aberta do Brasil $(\mathrm{UAB})^{5}$, o Programa Institucional de Bolsas de Iniciação à Docência (PIBID) e a Coordenação de Aperfeiçoamento de Pessoal de Nível Superior (Capes).

Estudo anterior realizado por Masson (2012) destaca que alguns autores como Ruiz (2007), Freitas (2007), Aguiar (2007), Mendonça (2007), Gracindo (2007) e Cara (2007) questionaram a forma como se deu a elaboração do PDE, pois não houve uma discussão ampliada com as instituições e os profissionais da educação. Para a elaboração do que viria a ser o Plano de Desenvolvimento da Educação (BRASIL, 2007c), participaram diversos setores como ONGs, empresários, Undime ${ }^{6}$, Consed ${ }^{7}$, excluindo-se outros setores do debate.

Quanto à Universidade Aberta do Brasil, o plano tem como objetivo proporcionar atividades de expansão da educação a distância em todo o território nacional. Segundo as propostas presentes no livro do PDE, a UAB dialoga com os objetivos do PNE e, dentre eles, está o de ampliar, a partir da colaboração da União, dos Estados e dos municípios, os programas de formação em serviço que assegurem a todos os professores a possibilidade de adquirir a qualificação mínima exigida pela Lei de Diretrizes e Bases da Educação Nacional, observando as diretrizes e os parâmetros curriculares (BRASIL, 2007c).

A LDB nº 9.394/96 (BRASIL, 2010a), em seu artigo 80, já estipulava que a instituição interessada poderia oferecer cursos superiores a distância, desde que solicitasse o seu credenciamento junto à União. O artigo $1^{\circ}$, do Decreto $n^{\circ} 5.622 / 05$ (BRASIL, 2005), determina que tais cursos tenham momentos presenciais, realizem a avaliação dos estudantes, estágios obrigatórios, apresentação de trabalho de conclusão de curso e atividades relacionadas a laboratórios de ensino, quando for o caso.

É notável o crescimento da educação a distância no Brasil, apesar de apresentar fragilidades, pois os polos de apoio presencial não possuem as mesmas condições de estudo e trabalho das instituições de Ensino Superior, prejudicando a inserção dos alunos num espaço acadêmico que possibilite a articulação entre ensino, pesquisa e extensão. Assim, a UAB tende a ser mais um espaço de profissionalização do que de

${ }^{5}$ Esta passou a existir a partir de junho de 2006, através do Decreto ${ }^{\circ} 5.800$ (BRASIL, 2006) e está a cargo da Diretoria de Educação a Distância do MEC, ligada a Capes, em parceria com a Seed (Secretaria de Estado da Educação). A UAB não é propriamente uma universidade, mas representa um sistema integrado por universidades públicas e oferece cursos de nível superior para a população que têm dificuldade de acesso à formação universitária, por meio do uso da metodologia da educação a distância, onde a prioridade é dada para os cursos de Licenciatura (CAPES, [20--]).

${ }^{6}$ União Nacional dos Dirigentes Municipais de Educação.

${ }^{7}$ Conselho Nacional de Secretários da Educação. 
efetiva formação integral dos sujeitos. Todavia, tal ação poderá contribuir para limitar a disseminação de cursos de formação a distância aligeirados e mercantilizados, pois a ênfase dada à oferta de cursos superiores a distância em universidades públicas poderá conferir-lhes maior grau de qualidade.

A proposta do Plano de Desenvolvimento da Educação (BRASIL, 2007c), de instituir programas de formação e implantar planos de carreira, cargos e salários para os profissionais da educação, deveria ser uma política de Estado, mas a impressão que se tem, ao se realizar uma análise sobre tal proposição, é de que não há muitos avanços. A diferença entre os municípios e estados em relação à estruturação da carreira e remuneração dos docentes também é outra questão que deveria ser considerada em nível nacional, já que a Resolução no 2, de 28 de maio de 2009 (BRASIL, 2009d), fixa as Diretrizes Nacionais para os Planos de Carreira e Remuneração dos Profissionais do Magistério da Educação Básica Pública.

Outra proposta do PDE para a formação docente é o Programa Institucional de Bolsa de Iniciação à Docência - PIBID. Este é um programa que visa conceder bolsas de iniciação à docência para alunos de cursos de licenciatura e para coordenadores e supervisores responsáveis e demais despesas a ele vinculadas (CAPES, 2008). A seleção é realizada por meio de editais para instituições de Ensino Superior que possuam cursos de licenciatura e que tenham firmado convênio ou acordo de cooperação com as redes de Educação Básica públicas dos municípios, dos Estados ou do Distrito Federal (MASSON, 2012). Dentre os programas de governo para a formação e valorização docente, o PIBID tem se destacado com uma proposta que tem apresentado bons resultados.

Em relação à Capes, esta, com a Lei no 11.502, de 11 de julho de 2007 (BRASIL, 2007b), ficou encarregada de subsidiar o Ministério da Educação em quase todas as áreas educacionais, inclusive a de formação de professores.

Das 28 ações estabelecidas pelo Plano de Metas Compromisso Todos pela Educação, destacam-se as medidas voltadas para a formação e valorização docente que foram incorporadas no PDE: a) instituir programa de formação e implantar plano de carreira, cargos e salários para os profissionais da educação; b) valorizar o mérito do trabalhador da educação, fixar regras claras, considerados mérito e desempenho, para nomeação e exoneração de diretor de escola.

As propostas estabelecidas para programas de formação e plano de carreira dos professores visam atender as necessidades educacionais e sociais, mas pouco se avança 
no sentido de uma verdadeira valorização do profissional docente e de uma formação com fundamentos teóricos sólidos. Além disso, a jornada de trabalho docente também precisa ser repensada, a fim de favorecer tanto o professor e a instituição em que ele atua. Nesse aspecto, Saviani (2007, p.1251) destaca que:

[...] essa carreira teria que estabelecer a jornada integral em um único estabelecimento de ensino, de modo que se pudessem fixar os professores nas escolas, tendo presença diária e se identificando com elas. E a jornada integral, de 40 horas semanais, teria que ser distribuída de maneira que se destinassem $50 \%$ para as aulas, deixando-se o tempo restante para as demais atividades. Com isso, os professores poderiam participar da gestão da escola; da elaboração do projeto político-pedagógico da escola; das reuniões de colegiado; do atendimento às demandas da comunidade e, principalmente, além da preparação das aulas e correção de trabalhos, estariam acompanhando os alunos, orientando-os em seus estudos e realizando atividades de reforço para aqueles que necessitassem.

A questão meritocrática também não deixa de ser problemática, pois a valorização do profissional pela sua produtividade não leva em consideração as reais condições de trabalho, recaindo somente sobre os profissionais da educação a responsabilidade em relação aos resultados da sua atividade. Analisando-se essas questões, percebe-se que a valorização docente não se dará somente pelo aumento da remuneração, mas, também, pela garantia de boas condições de trabalho, plano de carreira atrativo, formação inicial e continuada pautada em fundamentos teóricopráticos que possibilitem a apreensão das reais dificuldades a serem enfrentadas pelo profissional da educação.

\section{Formação e valorização docente: proposições do novo plano nacional de educação}

Historicamente, encontramos prenúncios de um Plano Nacional de Educação no início da República, com a necessidade de uma educação escolar para povo, que em sua maioria não era alfabetizado, para possibilitar o crescimento econômico do país.

Por muito tempo, embora houvesse tentativas de estabelecimento de um PNE, o primeiro, realmente aprovado, foi o de 2001 (BRASIL, 2001), mesmo com muitas tensões e embates políticos entre o governo e a sociedade civil organizada. A proposta da sociedade brasileira foi substituída pela do governo Fernando Henrique Cardoso, a qual desconsiderou os debates realizados pela sociedade civil. Para alguns avaliadores, como Valente e Romano (2002), o documento tornou-se apenas uma carta de intenção e 
a efetivação de várias de suas propostas acabaram não sendo cumpridas e "ignoradas" posteriormente, como por exemplo, a questão da formação do professor em nível superior que era para acontecer desde a aprovação da Lei de Diretrizes e Bases da Educação Nacional (BRASIL, 2010a).

Neste contexto, de indiferença com o planejamento educacional, destacamos o atraso na aprovação do novo PNE, que era para ter ocorrido em 2010, mas foi aprovado somente em 2014.

No processo de tramitação do novo PNE, primeiramente, o Projeto de Lei recebeu o $\mathrm{n}^{\circ}$ 8.035/2010 (BRASIL, 2010b), no entanto, quando este passou para a aprovação no Congresso Nacional recebeu o $n^{\circ}$ 103/2012 (BRASIL, 2012), com algumas alterações no texto. Assim, analisamos as metas de formação e valorização apresentadas na proposta do Projeto de Lei $n^{\circ}$ 8.035/2010 (BRASIL, 2010b) e as emendas a ele propostas, comparando com o que foi aprovado pela Lei $n^{\circ} 13.005 / 2014$.

As metas 15 e 16 estão relacionadas à formação de professores, tanto inicial, quanto de pós-graduação e continuada.

A meta 15 do Projeto de Lei destacava: “[...] Garantir, em regime de colaboração entre a União, os Estados, o Distrito Federal e os Municípios, que todos os professores da educação básica possuam formação específica de nível superior, obtida em curso de licenciatura na área de conhecimento em que atuam”. (BRASIL, 2010b, p.16).

A Meta 16 propôs: “[...] Formar 50\% dos professores da educação básica em nível de pós-graduação lato e stricto sensu, garantir a todos formação continuada em sua área de atuação". (BRASIL, 2010b, p.17).

Essas metas são de grande importância ao considerar-se o número significativo de professores da Educação Básica que ainda não possui formação em nível superior ou que estão exercendo uma atividade diferente da sua formação específica. Assim, podemos observar, no quadro abaixo, que o percentual de docentes com formação em nível superior manteve-se estável por algum tempo no cenário nacional, alcançando apenas em 2011 (exatamente dez anos depois), a meta estipulada no PNE anterior (2001-2011), no qual estava previsto que “[...] no prazo de dez anos, 70\% dos professores de educação infantil e de ensino fundamental (em todas as modalidades) possuam formação específica de nível superior, de licenciatura plena em instituições qualificadas". (BRASIL, 2001). 
Quadro 1- Percentual dos professores da Educação Básica com nível superior

\begin{tabular}{|c|c|c|c|c|c|c|c|}
\hline \multicolumn{2}{|c|}{} & \multicolumn{6}{c|}{ Proporção de Docentes por Grau de Formação } \\
\cline { 3 - 7 } & $\begin{array}{c}\text { Número de } \\
\text { Docentes }\end{array}$ & Incompleto & $\begin{array}{c}\text { Eomplet } \\
\text { ono }\end{array}$ & Total & $\begin{array}{c}\text { Normal/ } \\
\text { Magistério }\end{array}$ & $\begin{array}{c}\text { Sem } \\
\text { Normal/ } \\
\text { Magistério }\end{array}$ & $\begin{array}{c}\text { Educação } \\
\text { Superior }\end{array}$ \\
\hline $\mathbf{2 0 0 7}$ & 1.880 .910 & 0,2 & 0,6 & 30,8 & 25,3 & 5,5 & 68,4 \\
\hline $\mathbf{2 0 0 8}$ & 2.003 .700 & 0,2 & 0,5 & 32,5 & 25,7 & 6,7 & 66,8 \\
\hline $\mathbf{2 0 0 9}$ & 1.991 .606 & 0,2 & 0,5 & 31,6 & 24,5 & 7,1 & 67,8 \\
\hline $\mathbf{2 0 1 0}$ & 2.023 .748 & 0,2 & 0,4 & 30,5 & 22,5 & 8,1 & 68,8 \\
\hline $\mathbf{2 0 1 1}$ & 2.069 .251 & 0,2 & 0,4 & 25,4 & 19,0 & 6,5 & 74,0 \\
\hline $\mathbf{2 0 1 2}$ & 2.095 .013 & 0,1 & 0,3 & 21,5 & 16,0 & 5,5 & 78,1 \\
\hline
\end{tabular}

Fonte: MEC/Inep/Deed (BRASIL, 2012).

Assim, o alcance da meta deu-se apenas nos últimos dois anos (2011/2012), o que demonstra a implementação tardia da garantia de condições de formação. Entretanto, vale destacar que mesmo tardio este aumento acorreu, principalmente, através da formação a distância, cujas limitações já foram destacadas. Neste panorama, teríamos até 2018 atingido 100\% de docentes com nível superior, independente da questão da qualidade da formação. Mas, ao mesmo tempo, a obrigatoriedade da educação escolar dos 4 aos 17 anos (já prevista na Emenda Constitucional $n^{\circ}$ 59, de 2009 (BRASIL, 2009b)) somada a Lei $n^{\circ}$ 12.796/2013 (BRASIL, 2013), que aceita a admissão de professores de nível médio na modalidade normal para Educação Infantil e anos iniciais do Ensino Fundamental, é provável que ocorra um aumento na contratação de novos profissionais sem nível superior, como já vem ocorrendo em muitas regiões do país.

Esta maneira de tentar resolver o problema da formação de professores não é novidade, pois no ano de 1990, por exemplo, o Estado tentou resolver, emergencialmente, o problema da falta de professores, quando o Conselho Pleno (CP) por meio da Resolução $n^{\circ}$ 2/1997 (BRASIL, 1997) planejou programas de complementação pedagógica para bacharéis de qualquer área, que tivessem interesse em lecionar na Educação Básica. No governo de Luiz Inácio Lula da Silva (2003-2011), é visível a tentativa de resolução da inadequação na formação dos docentes, através de diferentes ações ${ }^{8}$ (MASSON, 2009).

\footnotetext{
${ }^{8}$ Rede Nacional de Formação Continuada de Professores, Pró-licenciatura, Proinfantil, Programa de Incentivo à Formação Continuada de Professores do Ensino Médio, Prolind, Licenciatura em Educação Profissional e Tecnológica e Programa de Consolidação das Licenciaturas.
} 
Essas tentativas de resolução imediatista demonstra a falta de um planejamento de longo prazo que represente um efetivo interesse em valorizar a categoria docente, o que acaba ocasionando uma desmotivação nos professores para a permanência na carreira docente.

A ampliação da formação dos profissionais pode se caracterizar como um avanço qualitativo, entretanto, há a necessidade de ações que promovam a concretização das metas propostas, já que apenas ampliar a formação não garante a valorização profissional dos docentes, pois ela deve vir acompanhada de outras ações como, por exemplo, a melhoria das condições de trabalho.

Neste âmbito, destacamos a emenda modificativa à meta 15, proposta pela Associação Nacional de Pós-Graduação e Pesquisa em Educação (ANPED, 2011), a qual defende que a primeira formação superior deve ser preferencialmente na modalidade presencial, garantindo que todos os profissionais da educação possuam formação específica em nível superior até o final da década. Com o acréscimo que modifica a meta, a mesma delimita um prazo para o seu cumprimento, além de estabelecer que a formação inicial seja preferencialmente presencial, sendo realizada a distância somente nos casos de falta de vagas para o atendimento da demanda de uma região específica, o que poderá melhorar a formação dos profissionais da educação.

A Confederação dos Trabalhadores em Educação - CNTE (CNTE, 2011) também propôs uma emenda substitutiva à meta 15 , que foi aceita no documento do Fórum Nacional de Educação - FNE (BRASIL, 2011), a qual, embora esteja de acordo com o que foi preconizado na Lei de Diretrizes e Bases da Educação Nacional, $\mathrm{n}^{\circ}$ 9.394/96 (BRASIL, 2010a), não apresenta avanços, pois admite como formação mínima, para atuar na Educação Infantil e nos anos iniciais do Ensino Fundamental, o nível médio.

Considerando os limites da proposta do CNTE (2011), destacamos a proposta da ANPED (2011), pois esta trata igualmente todos os níveis da Educação Básica, além de estabelecer prazo para o seu cumprimento, garantindo, também, que a formação inicial aconteça preferencialmente de forma presencial.

O crescimento exponencial de cursos a distância, tanto de instituições públicas como privadas, é sinal da insuficiência de oferta de vagas para formação presencial de professores.

Segundo Scheibe (2010), a privação da vivência universitária nos mostra a necessidade de a primeira formação do professor ser em cursos de licenciaturas 
presenciais, pois, de acordo com ela, proporciona maior contato dos alunos com a vida universitária institucional, com profissionais envolvidos com processos de pesquisa em educação, com movimentos de luta para uma educação de qualidade e uma maior troca de experiências entre professor e aluno, o que enriqueceria sua formação, possibilitando melhor qualificação profissional, humana e desenvolvimento do compromisso social e político do magistério.

Para a meta 16, dentre as propostas, selecionamos a modificativa do Congresso Nacional, que foi aceita integralmente pelo FNE, somente com a mudança de alguns termos, no que diz respeito ao ano de planejamento e a aprovação do PNE no senado, estabelecendo porcentagens específicas para cada parcela de tempo, permitindo que a meta seja mais tangível.

Formar 35\% dos professores da educação básica em nível de pósgraduação lato e stricto sensu, até o quinto ano de vigência desta Lei, e $50 \%$ dos professores da educação básica em nível de pós-graduação lato e stricto sensu, até o último ano de vigência desta Lei, e garantir a todos formação continuada em sua área de atuação. (BRASIL, 2011, p.120).

Com relação à formação continuada em serviço, a meta deve garantir a possibilidade de todos os professores terem acesso, pois a formação continuada deve ser entendida como uma continuação da formação inicial, sem se distanciar da cultura acadêmica de problematização da realidade e do rigor no desenvolvimento da pesquisa. Assim, é importante garantir condições para a realização da formação continuada dos professores, para que esta possibilite o comprometimento e a motivação destes com a atividade pedagógica que desenvolvem.

No Projeto de lei da Câmara $n^{\circ}$ 103/2012 (BRASIL, 2012), a meta 15 e 16 tiveram algumas mudanças:

Meta 15: garantir, em regime de colaboração entre a União, os estados, o Distrito Federal e os municípios, no prazo de um ano de vigência deste PNE, política nacional de formação dos profissionais da educação de que tratam os incisos I, II e III do art. 61 da Lei $n^{\circ}$ 9.394/1996, assegurando-lhes a devida formação inicial, nos termos da legislação, e formação continuada em nível superior de graduação e pós-graduação, gratuita e na respectiva área de atuação.

O PL nº 8.035/2010 (BRASIL, 2010b) a meta 15 sugeria a formação em nível superior, mas nessa nova redação permaneceu a formação inicial em nível médio, 
conforme a LDB n ${ }^{\circ}$ 9394/96 (BRASIL, 1996) e a proposta da CNTE (2011) e do FNE.

Todavia, a aprovação final da meta recebeu a seguinte redação:

Meta 15: garantir, em regime de colaboração entre a União, os Estados, o Distrito Federal e os Municípios, no prazo de 1 (um) ano de vigência deste PNE, política nacional de formação dos profissionais da educação de que tratam os incisos I, II e III do caput do art. 61 da Lei no 9.394, de 20 de dezembro de 1996, assegurado que todos os professores e as professoras da educação básica possuam formação específica de nível superior, obtida em curso de licenciatura na área de conhecimento em que atuam.

A meta 16 permaneceu no Novo Plano Nacional de Educação (Lei $\mathrm{n}^{\circ}$ 13.005/2014), com as proposições anteriores, com exceção do estabelecimento de $35 \%$ de formados até o quinto ano de vigência da lei e algumas modificações no texto, apresentando a seguinte redação:

Meta 16: Formar, em nível de pós-graduação, $50 \%$ (cinquenta por cento) dos professores da educação básica, até o último ano de vigência deste PNE, e garantir a todos (as) os (as) profissionais da educação básica formação continuada em sua área de atuação, considerando as necessidades, demandas e contextualizações dos sistemas de ensino. (BRASIL, 2014).

As metas 17 e 18 estão relacionadas à valorização docente, as quais buscam aumento do piso salarial e implantação e consolidação de planos de carreira para os profissionais da educação. Logo, estas metas estão intimamente relacionadas, já que a valorização dos professores requer, como ponto de partida, a síntese entre uma formação de qualidade, maiores salários e melhores condições de trabalho.

A partir da análise de tais metas, a ANPED (2011) propôs a fusão das mesmas e modificação na redação, a qual foi incorporada no documento do FNE (BRASIL, 2011) e sua redação foi organizada da seguinte maneira:

Valorizar o magistério público da educação básica, a fim de IGUALAR o rendimento médio do profissional do magistério ao dos demais profissionais com escolaridade equivalente, por meio de permanente aumento real do poder de compra do piso salarial profissional nacional da categoria e sua vinculação aos planos de carreira de estados, distrito federal e municípios, assim como criar condições para a regulamentação do piso salarial e da carreira profissional aos demais trabalhadores da educação, com base no artigo 206, incisos V, VIII e parágrafo único da constituição federal. (BRASIL, 2011, p.122, grifo nosso). 
Historicamente a representação da docência como um dom ou uma vocação:

[...] afastou socialmente a categoria dos professores da ideia de uma categoria profissional de trabalhadores que lutam por sua sobrevivência, [...] o que determinou, e determina em muitos casos, as dificuldades que professores encontram em sua luta categorial por salários [...]. (GATTI, 2009, p.239).

Em 2008, buscando uma melhoria no salário dos docentes, foi sancionada a "Lei do Piso" (BRASIL, 2008), com um valor inicial de R\$ 950,00 (novecentos e cinquenta reais) mensais $^{9}$, para profissionais com formação em nível médio, cumprindo uma jornada de quarenta horas semanais de trabalho. No quadro a seguir, é possível comparar a disparidade da remuneração dos professores nos diferentes estados do país.

Quadro 2 - Salário médio dos professores da Educação Básica - Rede Municipal, para uma jornada de 40 horas semanais

\begin{tabular}{|c|c|c|c|c|c|c|c|}
\hline UF & 2003 & 2004 & 2005 & 2006 & 2007 & 2008 & 2009 \\
\hline Rondônia & 665 & 840 & 695 & 851 & 1,130 & 1,020 & 1,096 \\
\hline Acre & 954 & 1022 & 963 & 1,061 & 1,041 & 1,392 & 1,464 \\
\hline Amazonas & 744 & 916 & 938 & 1,120 & 1,323 & 1,459 & 1,287 \\
\hline Roraima & 1139 & 1013 & 1,318 & 1,336 & 1,299 & 1,246 & 1,859 \\
\hline Pará & 755 & 752 & 785 & 887 & 976 & 1,231 & 1,152 \\
\hline Amapá & 690 & 663 & 1,518 & 996 & 1,073 & 1,027 & 1,391 \\
\hline Tocantins & 693 & 673 & 693 & 792 & 1,033 & 1,515 & 1,121 \\
\hline Maranhão & 514 & 638 & 723 & 885 & 914 & 1,144 & 1,151 \\
\hline Piauí & 477 & 573 & 672 & 835 & 872 & 1,005 & 1,068 \\
\hline Ceará & 549 & 543 & 613 & 742 & 768 & 1,033 & 1,072 \\
\hline Rio Grande do Norte & 643 & 669 & 698 & 814 & 1,004 & 1,146 & 1,482 \\
\hline Paraíba & 692 & 675 & 837 & 826 & 1,023 & 1,081 & 1,209 \\
\hline Pernambuco & 604 & 668 & 739 & 765 & 893 & 960 & 1,046 \\
\hline Alagoas & 564 & 706 & 796 & 903 & 888 & 1,164 & 1,364 \\
\hline
\end{tabular}

${ }^{9} \mathrm{O}$ valor do piso é atualizado anualmente e o seu valor atual é de $\mathrm{R} \$ 1.917,78$. Vale destacar que seis estados (Mato Grosso do Sul, Rio Grande do Sul, Ceará, Paraná e Santa Catarina) entraram com uma Ação Direta de Inconstitucionalidade (ADIn $n^{\circ}$ 4167) no Supremo Tribunal Federal contra a Lei do Piso. Posteriormente, cinco governadores apoiaram o questionamento judicial do Piso (Roraima, São Paulo, Tocantins, Minas Gerais e Distrito Federal). Após julgamento do STF, houve rejeição da ação dos governadores. 


\begin{tabular}{|l|r|r|r|r|r|r|r|}
\hline Sergipe & 577 & 886 & 985 & 1,271 & 1,385 & 1,465 & 1,709 \\
\hline Bahia & 554 & 647 & 714 & 850 & 1,006 & 1,015 & 1,125 \\
\hline Minas Gerais & 801 & 896 & 1,083 & 1,021 & 1,254 & 1,359 & 1,504 \\
\hline Espírito Santo & 865 & 822 & 911 & 1,067 & 1,571 & 1,268 & 1,551 \\
\hline Rio de Janeiro & 1483 & 1454 & 1,473 & 2,005 & 1,662 & 1,828 & 1,891 \\
\hline São Paulo & 1227 & 1273 & 1,478 & 1,684 & 1,662 & 1,844 & 1,785 \\
\hline Paraná & 860 & 959 & 1,000 & 1,173 & 1,262 & 1,282 & 1,514 \\
\hline Santa Catarina & 873 & 931 & 1,128 & 1,177 & 1,138 & 1,288 & 1,539 \\
\hline Rio Grande do Sul & 1060 & 1217 & 1,262 & 1,473 & 1,475 & 1,763 & 1,717 \\
\hline Mato Grosso do Sul & 705 & 1062 & 1,053 & 1,303 & 1,440 & 1,505 & 1,607 \\
\hline Mato Grosso & 738 & 814 & 1.129 & 1,123 & 1,228 & 1,243 & 1,346 \\
\hline Goiás & 755 & 924 & 996 & 892 & 1,167 & 1,253 & 1,233 \\
\hline Distrito Federal & & & & & & & \\
\hline Brasil & $\mathbf{8 5 0}$ & $\mathbf{9 1 4}$ & $\mathbf{1 0 0 3}$ & $\mathbf{1 1 6 1}$ & $\mathbf{1 2 3 4}$ & $\mathbf{1 3 5 7}$ & $\mathbf{1 4 2 5}$ \\
\hline
\end{tabular}

Fonte: IBGE (BRASIL, 2013a, p.100).

No quadro, é possível perceber a diferença que existe entre os entes federados em relação ao salário médio dos professores da Educação Básica, mesmo com a existência de um piso salarial. Além de ser um piso que valoriza insuficientemente a atividade do professor, se comparado com o de outras profissões com o mesmo nível de formação, há também a preocupação com a garantia de melhores condições de trabalho, como por exemplo, os requisitos de carga horária em sala de aula e para planejamento, número de alunos, etc. Novas pesquisas devem apontar se todos os "municípios" cumprem com esta referida lei, pois ao considerarmos os Planos de Carreira, a situação de descumprimento é muito complicada.

Em maio de 2009, as Diretrizes Nacionais para os Planos de Carreira e Remuneração dos Profissionais da Educação Básica Pública foram aprovadas pela Resolução $n^{\circ}$ 2/2009 (BRASIL, 2009d) contemplando: acesso a carreira por concurso de provas e títulos, adequado ao perfil profissional; progressão salarial na carreira, contemplando experiência, tempo de serviço, desempenho, atualização e aperfeiçoamento profissional; jornada preferencial em tempo integral, com parte de tempo destinada à formação continuada, com período reservado a estudos, planejamento e avaliação; propõe critérios para a proporção professor/aluno, conforme o nível de atendimento e idade. 
Essas questões são consideradas como referências mínimas a serem contempladas nos planos de carreira, que podem ser complementadas de acordo com as necessidades e características de cada região, no entanto, nem sempre as previstas em lei são asseguradas, evidenciando a necessidade de maior acompanhamento e fiscalização dos entes federados, na tentativa de possibilitar maiores avanços.

No PLC $\mathrm{n}^{\circ}$ 103/2012 (BRASIL, 2012), as metas 17 e 18 estavam dispostas separadamente com algumas modificações no texto, no entanto, contemplavam as proposições anteriores da sociedade civil organizada.

Meta 17: Valorizar os profissionais do magistério das redes públicas de educação básica de forma a equiparar seu rendimento médio ao dos demais profissionais com escolaridade equivalente, até o final do sexto ano de vigência deste PNE.

Meta 18: Assegurar, no prazo de dois anos, a existência de planos de carreira para os profissionais da educação básica e superior pública de todos os sistemas de ensino e, para o plano de carreira dos profissionais da educação básica pública, tomar como referência o piso salarial nacional profissional, definido em lei federal, nos termos do inciso VIII do art. 206 da Constituição Federal. (BRASIL, 2012).

Tais metas foram mantidas com essa redação na aprovação do novo Plano Nacional de Educação (Lei no 13.005/2014).

Através da análise da proposta de formação (metas 15 e 16) e de valorização docente (metas 17 e 18), evidenciou-se que as políticas educacionais, como síntese de um processo de discussão entre diferentes sujeitos sociais, acabam privilegiando determinadas ações que não oferecem condições de mudança significativa.

As políticas educacionais acabam reproduzindo os interesses da classe dominante ao defenderem um discurso progressista para demonstrar a "tentativa" de melhorar as condições de formação e de vida da classe trabalhadora, mas na realidade não oferecem condições adequadas para um efetivo avanço. Como exemplo, podemos destacar a aprovação da Lei n 12.796, de 4 de abril de 2013 (BRASIL, 2013b), a qual altera a LDB, para dispor sobre a formação dos profissionais da educação e dar outras providências. O Art. 62 passa a ter a seguinte redação:

A formação de docentes para atuar na educação básica far-se-á em nível superior, em curso de licenciatura, de graduação plena, em universidades e institutos superiores de educação, admitida, como formação mínima para o exercício do magistério na educação infantil e nos 5 (cinco) primeiros anos do ensino fundamental, a oferecida em 
nível médio na modalidade normal. (BRASIL, 2013b, p.3, grifo nosso).

Pode-se observar que, essencialmente, não houve alteração quanto à exigência mínima de formação, pois apenas ocorreu uma modificação quanto aos anos iniciais do Ensino Fundamental, pela sua ampliação já prevista na Lei no 11.274 , de 6 de fevereiro de 2006 (BRASIL, 2006).

Em que pese a luta empreendida por diferentes entidades como a Associação Nacional pela Formação dos Profissionais da Educação (ANFOPE) e a Associação Nacional de Pós-Graduação e Pesquisa em Educação (ANPED, 2011) para que a formação mínima admitida fosse em nível superior, a Lei $\mathrm{n}^{\circ} 12.796$ (BRASIL, 2013b) representa um retrocesso histórico. Vale destacar que a LDB, nas disposições transitórias, Art. 87, § 4, já previa que “[...] até o fim da Década da Educação somente serão admitidos professores habilitados em nível superior ou formados por treinamento em serviço ${ }^{10}$.

Passadas quase duas décadas da aprovação da LDB, ainda não avançamos para a garantia da formação do professor em nível superior, condição que consideramos indispensável para a sua profissionalização e valorização. Além disso, destacamos o esforço empreendido com a Política Nacional de Formação de Profissionais do Magistério da Educação Básica - Decreto nº 6.755/2009 (BRASIL, 2009a), com o Plano Nacional de Formação de Professores da Educação Básica - Parfor - Portaria n 9/2009 (BRASIL, 2009c) e com o Novo Plano Nacional de Educação - Lei n ${ }^{\circ}$ 13.003/2014 (BRASIL, 2014) bem como os significativos investimentos realizados que acabam entrando em contradição com o disposto na Lei n ${ }^{\circ}$ 12.796/2013 (BRASIL, 2013b).

\section{Considerações finais}

O presente artigo teve como finalidade analisar as propostas das políticas educacionais atuais para a formação e valorização docente. Percebe-se que a valorização dos profissionais da educação é muito ampla e que, na organização das leis referentes à formação e valorização docente, não são consideradas questões como jornada de trabalho num único estabelecimento, menor número de alunos, materiais didáticos adequados, remuneração, que estejam aliados à formação de qualidade do professor.

Quanto à questão salarial, “[...] os professores brasileiros, em especial aqueles que se dedicam ao início da formação educacional de crianças, nunca foram

${ }^{10}$ Neste contexto, o fim da década seria em 20 de dezembro de 2006. 
remunerados adequadamente". (CAMPOS, 2002; TANURI, 2000; RABELO, 2010 apud FLACH, 2013). Essa situação precisa ser repensada ao se estabelecerem as novas políticas educacionais, como os novos planos de carreira. Sabe-se que parte do investimento em educação é para garantir a remuneração dos professores, mas o que nota-se, também, é que essa remuneração, apesar de apresentar avanços com o estabelecimento do piso, ainda é insuficiente, já que o professor tem de investir em formação continuada, estudo e aperfeiçoamento, além de garantir a sua sobrevivência como todos os demais trabalhadores.

Apesar de se perceber a necessidade de políticas que considerem essas questões de forma ampla, fica claro que as medidas dos governos se distanciam cada vez mais destas, isso porque os problemas existentes nas escolas não são somente de origem educacional, pois estão relacionados aos problemas econômicos e sociais, mais amplos.

Reconhecendo a amplitude e complexidade em que se dá o processo de formação e valorização docente, pelos condicionantes econômicos, políticos, sociais e históricos, destacamos a necessidade de um maior investimento para a educação, através de políticas de curto, médio e longo prazo, de uma maior valorização dos profissionais, garantindo uma sólida formação teórico-prática aos docentes, em nível superior.

Há a necessidade de se desenvolver uma educação crítica, com "atividades educativas emancipadoras" como propõe Tonet $(2012)^{11}$, para isso, faz-se mister que ocorra um maior investimento em políticas de formação que visem à uma formação teórica consistente, que supere a superficialidade e o aligeiramento para atender demandas emergenciais, pois elas se tornarão permanentes, caso não ocorra uma efetiva valorização que torne a carreira do magistério atrativa, a ponto de garantir a permanência no exercício da profissão.

\section{TEACHER INSTRUCTION AND VALORIZATION POLICIES: AN ANALYSIS OF THE EDUCATION DEVELOPMENT PLAN AND TARGETS PROPOSED FOR THE NEW EDUCATION NATIONAL PLAN}

\footnotetext{
${ }^{11}$ Segundo Tonet (2012, p.39), para o desenvolvimento de atividades educativas emancipadoras "[...] além de ter clareza do objetivo final a ser atingido, também é necessário compreender bem a lógica que preside a sociedade capitalista e a natureza atual da crise; ter clareza acerca da natureza e das funções sociais da educação, de modo a nem subestimá-la e nem superestimá-la; ter um domínio tal da área com a qual se trabalha que permita oferecer o melhor conhecimento possível aos educandos e, finalmente, articular as lutas específicas da categoria dos educadores com as lutas mais gerais".
} 
ABSTRACT: This paper aims to analyze how the instruction and valorization of teachers are catered for in the current educational policies. The research carried out was bibliographic and documental, based on the historical and dialectical materialism. The documents surveyed were the Education Development Plan (BRASIL, 2007c), the Law project $n^{\circ} .8 .035 / 2010$ (BRASIL, 2010b) and the law project $n^{\circ}$ 103/2012 (BRASIL, 2012), which are concerned with the new Education National Plan, as well as documents that propose amendments of different entities and were incorporated by the Education National Forum (BRASIL, 2011). The study identified that the objectives set by the Education Development Plan (BRASIL, 2007c) and the targets of the New Education national Plan (BRASIL, 2014) for teacher instruction and valorization do not take into consideration objective issues, such as school infrastructure, working hours in the same school, suitable teaching material, amongst other needs. Finally, we highlight that teacher instruction and valorization should be linked to the fight for better working conditions. Thus, there is a necessity of investment in education, through short, medium and long term policies, better valorization of teachers and solid instruction for teachers and students, with the aim to create possibilities of qualitative educational transformation which will contribute to the human development.

KEY WORDS: Instruction policies. Teacher valorization. Education National Plan. Education Development Plan.

\section{REFERÊNCIAS}

AGUIAR, M. A. Atuação política: o querer, o poder e o fazer. Retratos da Escola, Brasília, n.1, 2007.

ANPED. ASSOCIAÇÃO NACIONAL DE PÓS-GRADUAÇÃO E PESQUISA EM EDUCAÇÃO. Documento: por um Plano Nacional de Educação (2011-2020) como política de estado. Rio de Janeiro: Armazém das Letras, 2011.

BRASIL. Decreto $\mathbf{n}^{\mathbf{0}}$ 5.622, de 19 de dezembro de 2005. Regulamenta o art. 80 da Lei 9394/96, de 20 de dezembro de 1996. Brasília: Senado Federal, 2005. Disponível em: <http://www.planalto.gov.br/ccivil_03/_Ato2004-2006/2005/decreto/D5622.htm>.

Acesso em: 24 ago. 2012.

Decreto $\mathrm{n}^{\mathrm{o}} 5.800$, de 8 de junho de 2006. Dispõe sobre o Sistema Universidade Aberta do Brasil - UAB. Diário Oficial da União, Brasília, p.4, 9 jun. 2006. Seção 1.

Decreto $n^{0}$ 6.094, de 24 de abril de 2007. Dispõe sobre a implementação do Plano de Metas Compromisso Todos pela Educação, pela União Federal, em regime de colaboração com Municípios, Distrito Federal e Estados, e a participação das famílias e da comunidade, mediante programas e ações de assistência técnica e financeira, visando a mobilização social pela melhoria da qualidade da educação básica. Brasília: Senado Federal, 2007a. Disponível em: <http://www.planalto.gov.br/ccivil_03/_ato20072010/2007/ decreto/d6094.htm>. Acesso em: 10 set. 2013.

Decreto $n^{0}$ 6.755, de 29 de janeiro de 2009. Institui a Política Nacional de Formação de Profissionais do Magistério da Educação Básica, disciplina a atuação da Coordenação de Aperfeiçoamento de Pessoal de Nível Superior - CAPES no fomento a 
programas de formação inicial e continuada, e dá outras providências. Brasília: Senado Federal, 2009a. Disponível em: <http://www.planalto.gov.br/ccivil 03/ato20072010/2009/Decreto/D6755.htm>. Acesso em: 05 set. 2013.

Emenda Constitucional $\mathbf{n}^{0}$ 59, de 11 de novembro de 2009. Dá nova redação aos incisos I e VII do art. 208, de forma a prever a obrigatoriedade do ensino de quatro a dezessete anos e ampliar a abrangência dos programas suplementares para todas as etapas da educação básica, e dá nova redação ao $\S 4^{\circ}$ do art. 211 e ao $\S 3^{\circ}$ do art. 212 e ao caput do art. 214, com a inserção neste dispositivo de inciso VI. Brasília: Senado Federal, 2009b. Disponível em: <http://www.planalto.gov.br/ccivil_03/constituicao/Emendas/Emc/emc59.htm>. Acesso em: 30 out. 2012.

Fórum Nacional de Educação. Emendas apresentadas ao Plano Nacional de

Educação. Brasília: Ministério da Educação, 2011. Disponível em: <http://fne.mec.gov.br/images/pdf/relatorio_final_ 140911. pdf〉. Acesso em: 14 mai. 2012.

Fórum Nacional de Educação. Notas técnicas PNE 2011-2020. Brasília: Ministério da Educação, 2013a. Disponível em: <http://fne.mec.gov.br/images/pdf/notas_tecnicas_pne_2011_2020.pdf > Acesso em: 30 ago. 2013.

Lei de Diretrizes e Bases da Educação Nacional. Lei no 9.394, de 20 de dezembro de 1996. 5.ed. Brasília: Câmara dos Deputados, 2010. Disponível em: $<$ http://www.ufal.edu.br/unidadeacademica/igdema/ institucional/documentos/ldb-leide-diretrizes-e-bases-da-educacao-nacional>. Acesso em: 08 jul. 2012.

Lei $\mathbf{n}^{\mathbf{0}}$ 11.274, de 6 de fevereiro de 2006. Altera a redação dos arts. 29, 30, 32 e 87 da Lei $n^{\circ}$ 9.394, de 20 de dezembro de 1996, que estabelece as Diretrizes e Bases da Educação Nacional, dispondo sobre a duração de 9 (nove) anos para o ensino fundamental, com matrícula obrigatória a partir dos 6 (seis) anos de idade. Brasília: Senado Federal, 2006. Disponível em: <http://www.planalto.gov.br/ccivil_03/_Ato2004-2006/2006/Lei/L11274.htm>. Acesso em: 24 ago. 2012.

Lei $\mathbf{n}^{\mathbf{0}}$ 11.502, de 11 de julho de 2007. Modifica as competências e a estrutura organizacional da fundação Coordenação de Aperfeiçoamento de Pessoal de Nível Superior - CAPES. Brasília: Senado Federal, 2007b. Disponível em <http://www.planalto.gov.br/ccivil_03/_Ato2007-2010/2007/Lei/L11502.htm>. Acesso em: 09 jun. 2012.

Lei $n^{\circ}$ 11.738, de 16 de julho de 2008. Regulamenta a alínea "e" do inciso III do caput do art. 60 do Ato das Disposições Constitucionais Transitórias, para instituir o piso salarial profissional nacional para os profissionais do magistério público da educação básica. Brasília: Senado Federal, 2008. Disponível em: <http://www.planalto.gov.br/ccivil_03/_ato2007-2010/2008/lei/111738.htm>. Acesso em: 03 abr. 2012.

Lei $\mathbf{n}^{\mathbf{0}}$ 12.796, de 4 de abril de 2013. Altera a Lei $\mathrm{n}^{0}$ 9.394, de 20 de dezembro

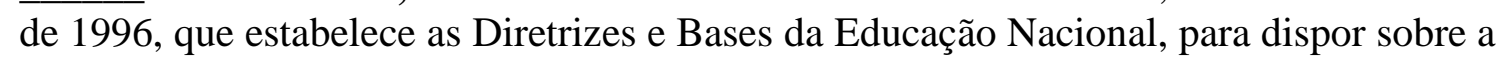
formação dos profissionais da educação e dar outras providências. Brasília: Senado 
Federal,

$2013 b$.

Disponível

em:

$<$ http://blogproinfanciabahia.wordpress.com/2013/04/05/lei-12-796-de-4-de-abril-de-

2013-sancionada-pela-presidente/>. Acesso em: 19 abr. 2013.

O Plano de Desenvolvimento da Educação: Razões, princípios e programas.

Brasília: MEC, 2007c.

Plano Nacional de Educação. Lei no 10.172, de 9 de janeiro de 2001.

Brasília: Senado Federal, 2001. Disponível em:

<http://www.planalto.gov.br/ccivil_03/leis/leis_2001/110172.htm>. Acesso em: 6 jul.

2012.

Plano Nacional de Educação. Lei no 13.003, de 25 de junho de 2014. Aprova

o Plano Nacional de Educação - PNE e dá outras providências. Brasília: Senado

Federal, 2014. Disponível em: <http://www.planalto.gov.br/CCIVIL_03/_Ato2011-

2014/2014/Lei/L13005.htm> Acesso em: 20 dez. 2014.

Portaria Normativa $\mathrm{n}^{\circ}$ 9, de 30 de junho de 2009. Institui o Plano Nacional de Formação dos Professores da Educação Básica no âmbito do Ministério da Educação. Diário Oficial da União, Brasília, DF, n.123, 1 jul. 2009c. Disponível em: <http://www.ifam.edu.br/portal/images/file/0000018614-Portaria\%2009_Parfor.pdf >.

Acesso em: 12 set. 2013.

. Projeto de Lei da Câmara no 103/2012. Plano Nacional de Educação 2011-

2020. Brasília: Senado Federal, 2012. Disponível em: <http://www.senado.gov.br/atividade/ materia/getPDF.asp? $\mathrm{t}=115871 \& \mathrm{tp}=1>$. Acesso em: 02 set. 2013.

Projeto de Lei $\mathbf{n}^{\circ}$ 8.035/2010. Plano Nacional da Educação 2010-2020. Brasília: Câmara dos Deputados, 2010. Disponível em: <http://www.camara.gov.br/proposicoesWeb/fichadetramitacao?id Proposicao=49 $\underline{0116 \mathrm{pdf}>}$. Acesso em: 12 jul. 2011.

Resolução no 2, de 26 de junho de 1997. Dispõe sobre os programas especiais de formação pedagógica de docentes para as disciplinas do currículo do ensino fundamental, do ensino médio e da educação profissional em nível médio. Brasília: MEC, $1997 . \quad$ Disponível em: <http://portal.mec.gov.br/setec/arquivos/pdf_legislacao/tecnico/ legisla_tecnico_resol02_26junho_1997.pdf>. Acesso em: 12 ago. 2012.

Resolução no 2, de 28 de maio de 2009. Fixa as Diretrizes Nacionais para os Planos de Carreira e Remuneração dos Profissionais da Educação Básica Pública. Brasília, 2009d. Disponível em: <http://portal.mec.gov.br /dmdocuments/resolucao_cne_ceb002_2009.pdf> Acesso em: 13 set. 2012.

CAMPOS, R. F. A reforma da formação inicial dos professores da educação básica nos anos de 1990: desvelando as tessituras da proposta governamental. 2002. $231 \mathrm{f}$. Tese (Doutorado em Educação) - Centro de Ciências da Educação, Universidade Federal de Santa Catarina, Florianópolis, 2002.

CAPES. Sobre a UAB. Brasília: UAB, [20--]. Disponível em: <http://uab.capes.gov.br/index.php/sobre-a-uab>. Acesso em: 16 jun. 2012. 
PIBID - Programa Institucional de Bolsa de Iniciação à Docência. Brasília: Ministério da Educação, 2008. Disponível em: <http://www.capes.gov.br/educacaobasica/capespibid>. Acesso em: 20 jul.2013.

CARA, D. Plano de Desenvolvimento da Educação: ausências e limitações. Retratos da Escola, Brasília, n.1, 2007.

CNTE. CONFEDERAÇÃO NACIONAL DOS EDUCADORES EM EDUCAÇÃO. Documento: PNE em debate pelos/as trabalhadores/as em educação. Brasília: CNTE, 2011. Disponível em: <http://www.cnte.org.br/index.php/comunica\%C3\%A7\%C3\%A3o/artigos/7585?task=vi ew>. Acesso em: 14 mai. 2012.

FLACH, S. Quanto vale o trabalho do professor? Desvelando o processo de desvalorização salarial em Ponta Grossa - PR. Práxis Educativa, Ponta Grossa, v.8, n.1, p.63-84, jan./jun. 2013.

FREITAS, L. C. PDE: responsabilidades e desafios. Retratos da Escola, Brasília, n.1, 2007.

GATTI, B. A. (Coord.). Professores do Brasil: impasses e desafios. Brasília: UNESCO, 2009.

GRACINDO, R. V. Notas sobre a educação básica no PDE. Retratos da Escola, Brasília, n.1, 2007.

MASSON, G. Implicações do Plano de Desenvolvimento da Educação para a formação de professores. Ensaio: Avaliação e Políticas Públicas em Educação, Rio de Janeiro, v. 20, n.74, p.165-184, jan./mar. 2012.

Políticas de formação de professores: as influências do neopragmatismo da agenda pós-moderna. 2009. 245 f. Tese (Doutorado em Educação) - Centro de Ciências da Educação, Universidade Federal de Santa Catarina, Florianópolis, 2009.

MENDONÇA, E. F. A educação é um direito de cidadania. Retratos da Escola, Brasília, n.1, 2007.

MÉSZÁROS. I. Para além do capital: rumo a uma teoria da transição. São Paulo: Boitempo, 2002.

OLIVEIRA, D. A. et al. Documento: por um Plano Nacional de Educação (2011-2020) como política de Estado. Revista Brasileira de Educação, Rio de Janeiro, v.16, n.47, p.483-492, mai./ago. 2011.

RUIZ, A. I. Ausências do PDE. Retratos da Escola, Brasília, n.1, 2007.

SAVIANI, D. Formação de professores: aspectos históricos e teóricos do problema no contexto brasileiro. Revista Brasileira de Educação, v. 14, n. 40, jan./abr. 2009.

O Plano de Desenvolvimento da Educação: análise do projeto do MEC. Educação e Sociedade, Campinas, v.28, n.100, p.1231-1255, out. 2007. 
SCHEIBE, L. Valorização e formação dos professores para a educação básica: questões desafiadoras para um novo plano nacional de educação. Educação e Sociedade, Campinas, v.31, n.112, p.981-1000, jul./set. 2010.

TANURI, L. M. História da formação de professores. Revista Brasileira de Educação, Rio de Janeiro, n.14. mai./ago. 2000.

TONET, I. Educação contra o capital. 2.ed. São Paulo: Instituto Lukács, 2012.

VALENTE, I.; ROMANO, R. PNE: Plano Nacional de Educação ou carta de intenção? Educação e Sociedade, Campinas, v.23, n.80, p.96-107, set. 2002. 